\author{
SANDIA REPORT \\ SAND2009-3909 \\ Unlimited Release \\ Printed July 2008
}

\title{
Shock Margin Testing of a One-Axis MEMS Accelerometer
}

\author{
Danelle M. Tanner, Ted B. Parson, and Thomas E. Buchheit
}

Prepared by

Sandia National Laboratories

Albuquerque, New Mexico 87185 and Livermore, California 94550

Sandia is a multiprogram laboratory operated by Sandia Corporation, a Lockheed Martin Company, for the United States Department of Energy's

National Nuclear Security Administration under Contract DE-AC04-94AL85000.

Approved for public release; further dissemination unlimited. 
Issued by Sandia National Laboratories, operated for the United States Department of Energy by Sandia Corporation.

NOTICE: This report was prepared as an account of work sponsored by an agency of the United States Government. Neither the United States Government, nor any agency thereof, nor any of their employees, nor any of their contractors, subcontractors, or their employees, make any warranty, express or implied, or assume any legal liability or responsibility for the accuracy, completeness, or usefulness of any information, apparatus, product, or process disclosed, or represent that its use would not infringe privately owned rights. Reference herein to any specific commercial product, process, or service by trade name, trademark, manufacturer, or otherwise, does not necessarily constitute or imply its endorsement, recommendation, or favoring by the United States Government, any agency thereof, or any of their contractors or subcontractors. The views and opinions expressed herein do not necessarily state or reflect those of the United States Government, any agency thereof, or any of their contractors.

Printed in the United States of America. This report has been reproduced directly from the best available copy.

Available to DOE and DOE contractors from

U.S. Department of Energy

Office of Scientific and Technical Information

P.O. Box 62

Oak Ridge, TN 37831

Telephone: $\quad$ (865) 576-8401

Facsimile: $\quad$ (865) 576-5728

E-Mail: $\quad$ reports@adonis.osti.gov

Online ordering: http://www.osti.gov/bridge

Available to the public from

U.S. Department of Commerce

National Technical Information Service

5285 Port Royal Rd.

Springfield, VA 22161

Telephone: (800) 553-6847

Facsimile: $\quad$ (703) 605-6900

E-Mail: $\quad$ orders@ntis.fedworld.gov

Online order: $\quad$ http://www.ntis.gov/help/ordermethods.asp?loc=7-4-0\#online

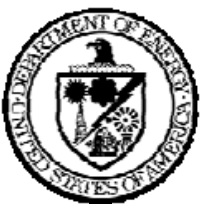


SAND2009-3909

Unlimited Release

Printed Month Year

\title{
Shock Margin Testing of a One-Axis MEMS Accelerometer
}

\author{
Danelle M. Tanner and Ted B. Parson \\ MEMS Core Technologies \\ Sandia National Laboratories \\ P.O. Box 5800 \\ Albuquerque, New Mexico 87185-MS1069 \\ Thomas E. Buchheit \\ Computational Materials Science and Engineering \\ Sandia National Laboratories \\ P.O. Box 5800 \\ Albuquerque, New Mexico 87185-MS0889
}

\begin{abstract}
Shock testing was performed on a selected commercial-off-the-shelf MicroElectroMechanical System (COTS-MEMS) accelerometer to determine the margin between the published absolute maximum rating for shock and the "measured" level where failures are observed. The purpose of this testing is to provide baseline data for isolating failure mechanisms under shock and environmental loading in a representative device used or under consideration for use within systems and assemblies of the DOD/DOE weapons complex. The specific device chosen for this study was the AD22280 model of the ADXL78 MEMS Accelerometer manufactured by Analog Devices Inc. This study focuses only on the shock loading response of the device and provides the necessary data for adding influence of environmental exposure to the reliability of this class of devices. The published absolute maximum rating for acceleration in any axis was $4000 G$ for this device powered or unpowered. Results from this study showed first failures at $8000 \mathrm{G}$ indicating a margin of error of two. Higher shock level testing indicated that an inplane, but off-axis acceleration was more damaging than one in the sense direction.
\end{abstract}




\section{ACKNOWLEDGMENTS}

We thank Ken Pohl for the circuit board design and the Shock lab, specifically Jack Heister for fixture design, DJ Kenny for running the tests, and Doug Vangoethem for shock level guidance. Shannon Crouch was extremely helpful in building up the circuit board and in the characterization of the accelerometers. 


\section{CONTENTS}

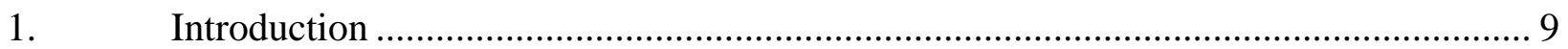

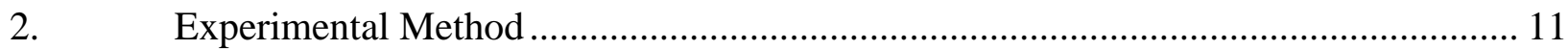

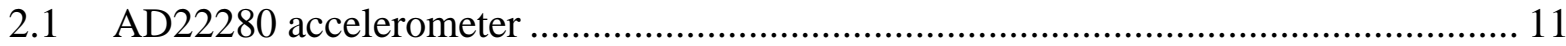

2.2 Experiment Preparation .................................................................................... 12

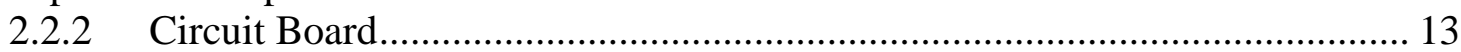

2.2.3. Initial Functionality Testing.......................................................................... 13

2.2.3. Fixture .............................................................................................. 14

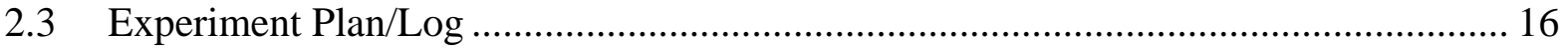

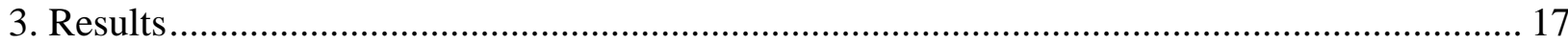

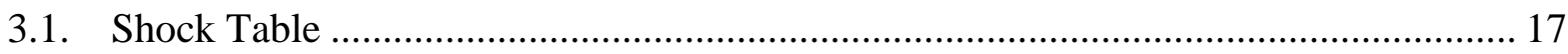

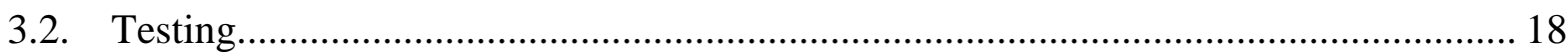

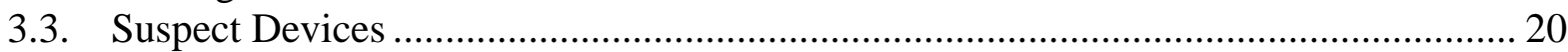

3.4. Analysis of Suspect Devices.................................................................................... 22

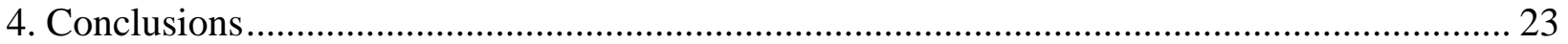

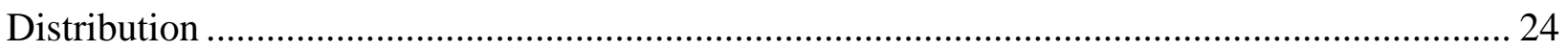

\section{FIGURES}

Figure 1. Paradigm to isolate failure mechanisms of MEMS devices subjected to combined thermal environment - shock loading environment common for qualification of components for

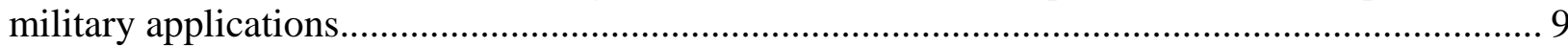
Figure 2. The accelerometer package is shown next to a scale with tic marks at $1.59 \mathrm{~mm}$. The package was 5 mm x 5 mm x 2 mm high. ...................................................................... 11 Figure 3. The output response is shown versus orientation in the earth's gravity field. ............ 12 Figure 4. This die of one of the AD22280 sensors shows the MEMS inter-digitated comb fingers in the center rectangle and the CMOS electronics surrounding it. ......................................... 12 Figure 5. On the left is the circuit designed to test accelerometer functionality. On the right is the PCB with 10 circuits to enable testing of 10 samples. The handles were used to hold the PCB

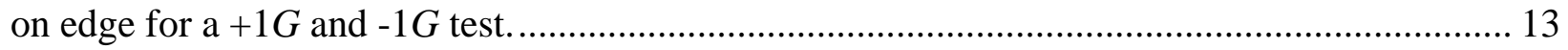
Figure 6. These histograms show the distribution of voltages for the four functionality tests. The mean of the distributions was $2.858 \mathrm{~V}, 2.475 \mathrm{~V}, 2.437 \mathrm{~V}$, and $2.513 \mathrm{~V}$ for the Self-Test, horizontal, $-G$, and $+G$ distributions, respectively. All three distributions have a standard deviation of

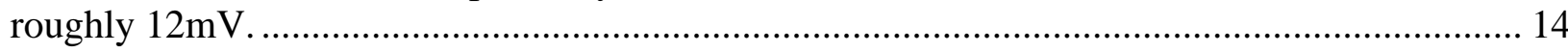
Figure 7. This drawing of the test fixture shows the defined coordinate system, the $+G$ direction, and the secure sample holder on each face. The ten single-axis samples were oriented according to the square diagram where the dot represents +sense direction.

Figure 8. The sample holder is shown with packages loaded in individual recessed areas. The package contact plate was a flexible web design to distribute the load from individual set screws as shown between the dotted lines................................................................................... 15 Figure 9. The fixture is shown mounted to the movable shock table. The carriage in the dotted rectangle was mechanically raised and held at the proper height with tensioned bungee cords (not 
shown). When the brake was released, this carriage slammed down into the felt layers (to define pulse shape) and apply the shock. 16 Figure 10. These are the measured amplitude and pulse durations of the carriage accelerometer.

Figure 11. The image on the left is a lid-sheared package after a $14,000 \mathrm{G}$ shock in the $-\mathrm{x}$ 18 direction. The image on the right shows the bottom of that same package. The arrow points to a crack in the package.

Figure 12. The image on the left shows the samples after a shock on $8000 \mathrm{G}$ in the indicated direction. The lid shear on the lower package is pointed out. Also, there were marks showing sample holder movement after the shock. On the right is the load distributor that held the packages in place. The rectangular (rather than square) imprint indicated motion in the G axis.19 Figure 13. Higher level shocks slammed the sample holder into the support screws and left an

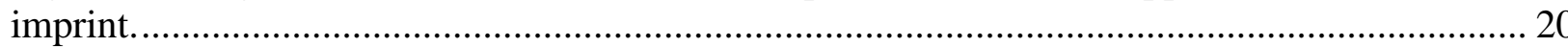

Figure 14. The AD22280 die is shown mounted in a cracked package.................................... 22

\section{TABLES}

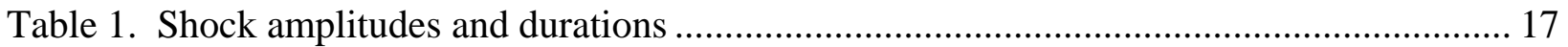

Table 2. Suspect Sample Categories from the Shock Testing ............................................. 21 


\section{NOMENCLATURE}

DOE Department of Energy

DOD Department of Defense

SNL Sandia National Laboratories

COTS Commercial off the shelf

ADI

Analog Devices, Incorporated

MOU Memorandum of Understanding

TCG Technical Coordinating Group 


\section{INTRODUCTION}

This study was conducted as a result of an objective proposed by the DOE/DOD MOU working group guiding the direction of the MEMS Reliability subtask element of TCG XIV, Materials Aging and Reliability. There are many commercial off the shelf (COTS) MEMS devices that are being considered for DOD munitions and other military applications. However, specifications for qualifying MEMS devices for use in military applications do not exist because the technology is relatively new and fundamentally different from electromechanical components fabricated using conventional fabrication technologies. Currently, military specifications, e.g. MIL-STD 883G, for microcircuits are considered to be the most relevant for evaluation and qualification of MEMS components. This study is the first in a proposed series of investigations to generate results that allow for the development of the set of military standards directly applicable to the qualification and reliability of MEMS components, a primary objective of the MEMS Reliability subtask. Failure induced by shock loading was investigated, and data was generated to set up a more generalized combined environment (thermal - shock loading) study (Figure 1) from which a revised qualification specification could be derived. This report is the result of the initial study that determined the relevant shock load for the overall approach outlined in the figure for a common "device of interest" for military applications.

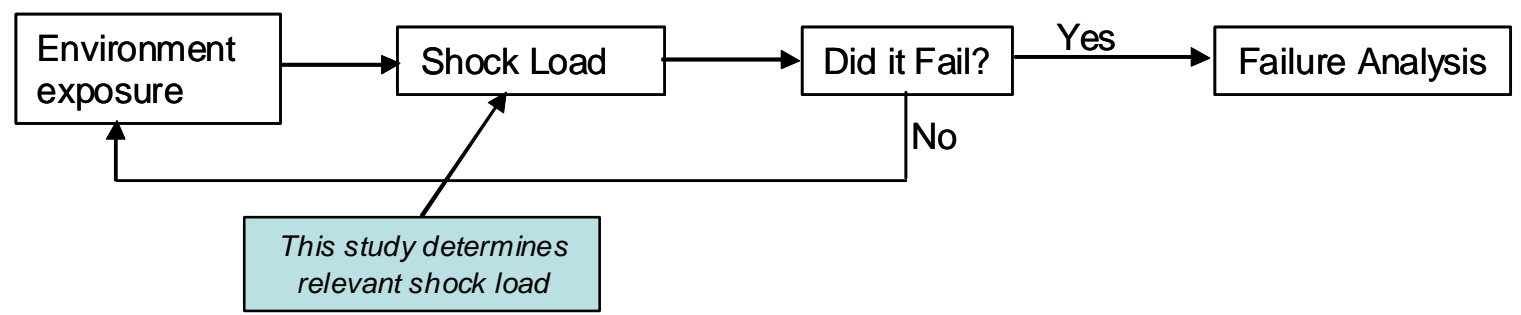

Figure 1. Paradigm to isolate failure mechanisms of MEMS devices subjected to combined thermal/shock environment common for qualification of components for military applications.

The MEMS "device of interest" selected for this study is a common device similar to a family of devices under consideration for use, or already being used within the military complex: the AD22280 model ADXL78 MEMS one-axis accelerometer manufactured by Analog Devices Inc. The AD22280 is a $\pm 50 \mathrm{G}$ sensor using ADI’s electrostatic plate capacitors and integrated microelectronics. Typical sensitivity is $38 \mathrm{mV}$ per $\mathrm{G}$. The self-test feature physically moves the comb fingers and can verify operation of the accelerometer. The operational specifications are conducive to military applications with an operational/storage temperature range of $-65^{\circ} \mathrm{C}$ to $+150^{\circ} \mathrm{C}$. The absolute maximum rating for acceleration in any axis, powered or unpowered, was 4000 G. These specifications were published by Analog Devices.

[http://www.analog.com/en/mems-and-sensors/imemsaccelerometers/adxl78/products/product.html] 
ADI also claims that stresses above these may cause permanent damage to the device and exposure to these absolute maximum ratings conditions for extended periods of time may affect device reliability. As a prelude to a combined thermal environment - shock loading study, the objective of these experiments was to determine the shock level that causes the AD22280 to fail and to isolate, if possible, the mechanisms of failure. 


\section{EXPERIMENTAL METHOD}

The following sections will describe the accelerometer, the experimental preparation steps, and finally the experiment.

\subsection{AD22280 accelerometer}

The ADXL22280 is a low power, complete single-axis accelerometer with signal conditioned voltage outputs that are on a single monolithic IC. This device measures acceleration with a fullscale range of $\pm 50 \mathrm{~g}$. It can also measure both dynamic acceleration (vibration) and static acceleration (gravity). The frequency resolution of the AD22280 is DC to $400 \mathrm{~Hz}$ (2.5 ms).

The ADXL22280 is the fourth-generation surface micromachined $i$ MEMS ${ }^{\circledR}$ accelerometer from ADI with enhanced performance and lower cost. Designed for use in front and side impact airbag applications, this product also provides a complete cost-effective solution useful for a wide variety of other applications.

The ADXL22280 is temperature stable and accurate over the military temperature range $\left(-55^{\circ} \mathrm{C}\right.$ to $\left.+125^{\circ} \mathrm{C}\right)$, with a self-test feature that fully exercises all the mechanical and electrical elements of the sensor with a digital signal applied to a single pin. The ADXL22280 is available in a $5 \mathrm{~mm} \times 5 \mathrm{~mm} \times 2 \mathrm{~mm}$, 8-terminal ceramic LCC package. The package is shown in Figure 2. The package orientation in the earth's gravitational field will generate different voltage outputs if aligned in the $\pm g$ direction as shown in Figure 3. These orientations provide two measurements of functionality in addition to the self-test.

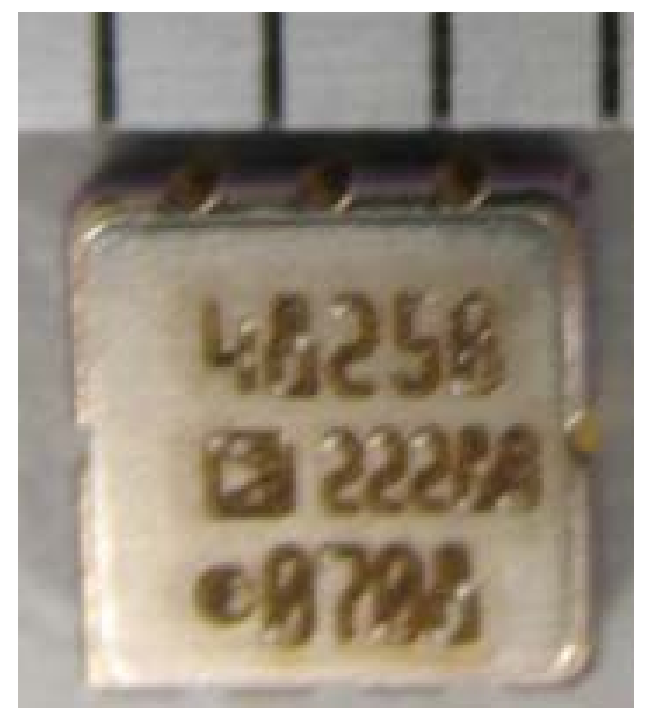

Figure 2. The accelerometer package is shown next to a scale with tic marks at $1.59 \mathrm{~mm}$. The package was $5 \mathrm{~mm} \times 5 \mathrm{~mm} \times 2 \mathrm{~mm}$ high. 


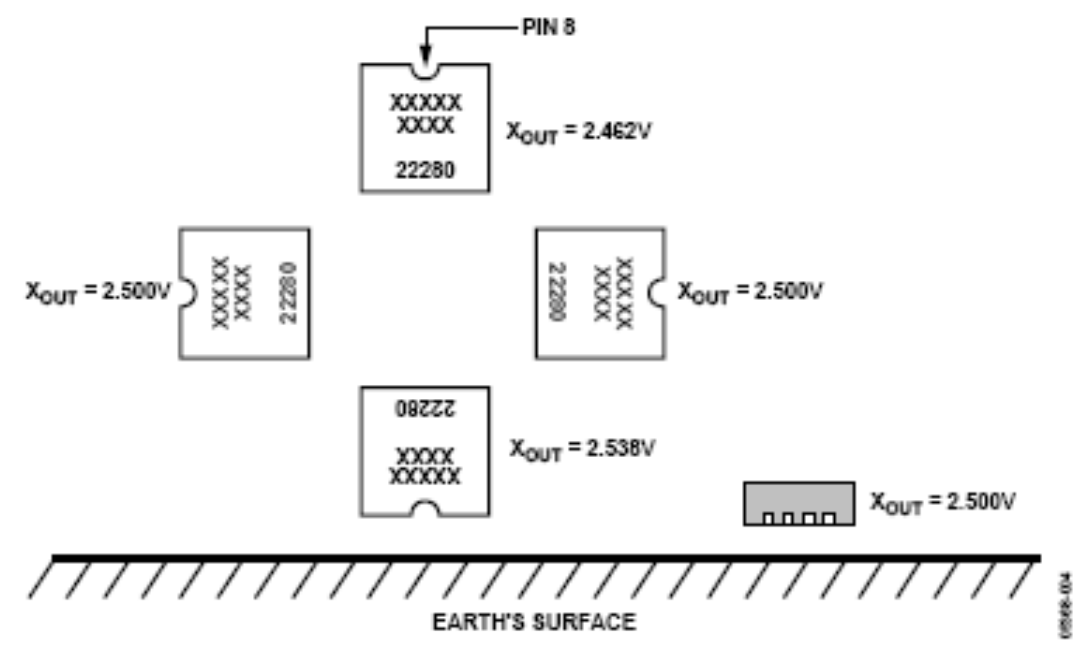

Figure 3. The output response is shown versus orientation in the earth's gravity field.

The ADI process typically fabricates the electrostatic MEMS device in the center of the die and caps it to prevent particle contamination and establish a controlled environment. The CMOS is then fabricated around the MEMS and provides the signals for the differential capacitive measurement. The die is shown in the following figure.

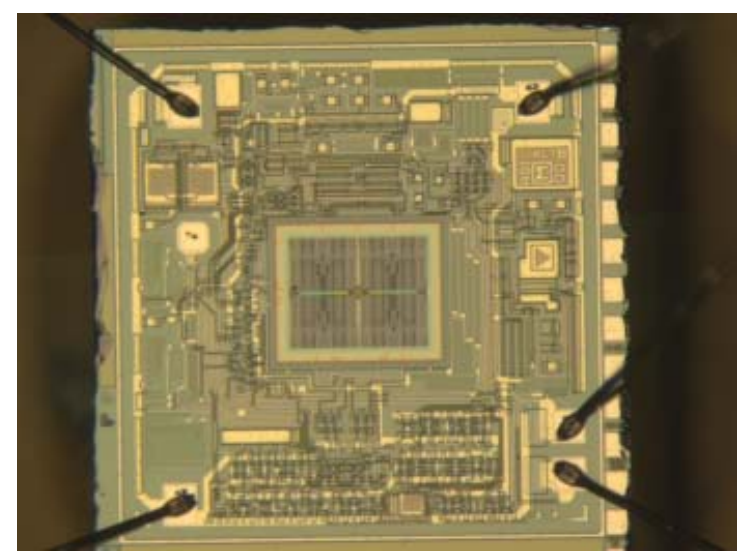

Figure 4. This die of one of the AD22280 sensors shows the MEMS inter-digitated comb fingers in the center rectangle and the CMOS electronics surrounding it.

\subsection{Experiment Preparation}

For these experiments, 500 samples were purchased from the electronics supplier, Digi-Key (www.digikey.com). The samples were divided into eight sets of 60 to provide for eight shock levels and groups of 10 samples on each of six axes. A true functionality test using gravity was possible because of the sensitivity of these samples $( \pm 50 \mathrm{G})$. This was an alternate check; in addition to the provided Self-Test of the MEMS device. 


\subsubsection{Circuit Board}

A printed circuit board was design and fabricated to test 10 accelerometer samples at a time. The test circuit and board layout are shown in Figure 5. One power supply was used to maintain $5.000 \mathrm{~V}$, and switches were utilized to apply power, output a voltage to the DMM (Digital MultiMeter, or run the self-test.

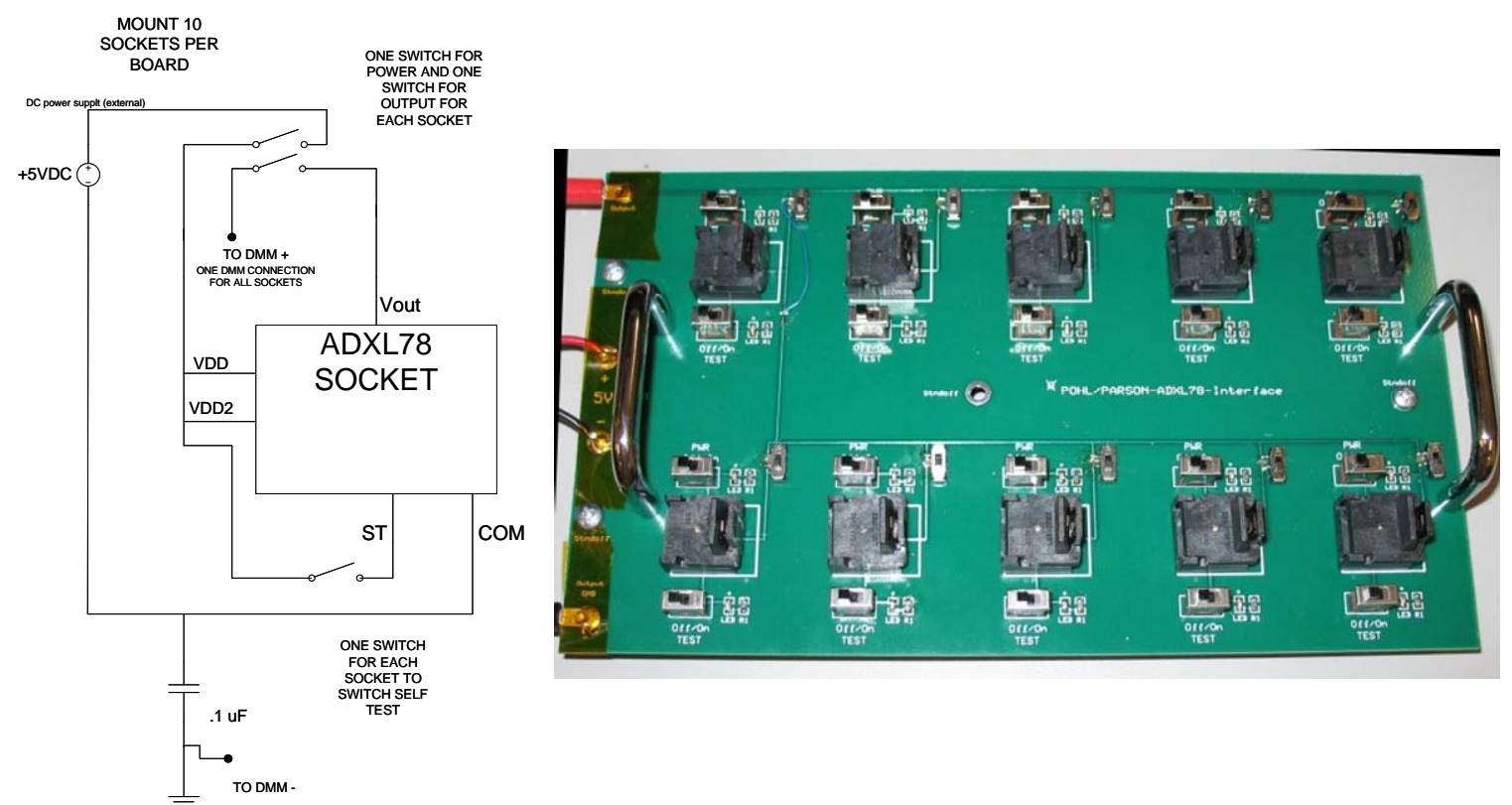

Figure 5. On the left is the circuit designed to test accelerometer functionality. On the right is the PCB with 10 circuits to enable testing of 10 samples. The handles were used to hold the PCB on edge for a $+1 G$ and $-1 G$ test.

\subsubsection{Initial Functionality Testing}

All of the samples were tested for functionality initially and all worked properly. The data recorded were self-test voltage output, horizontal voltage output, $+G$, and $-G$ voltage output. Histograms of this data are shown in Figure 6. These voltage output distributions were used to define the failure criteria for testing. Any voltage measured that was outside the limits of the distribution, was classified as suspect and further analysis could classify it as a failure. For example, the Self-Test voltages were between $2.824 \mathrm{~V}$ and $2.897 \mathrm{~V}$ which defines the range of acceptable voltages. Any voltage outside that range would represent a change and thus would be suspect. The acceptable ranges were

- Self-Test $2.824 \mathrm{~V}$ to $2.897 \mathrm{~V}$

- Horizontal $2.440 \mathrm{~V}$ to $2.516 \mathrm{~V}$

- $-G \quad 2.401 \mathrm{~V}$ to $2.477 \mathrm{~V}$

- $+G \quad 2.477 \mathrm{~V}$ to $2.553 \mathrm{~V}$ 

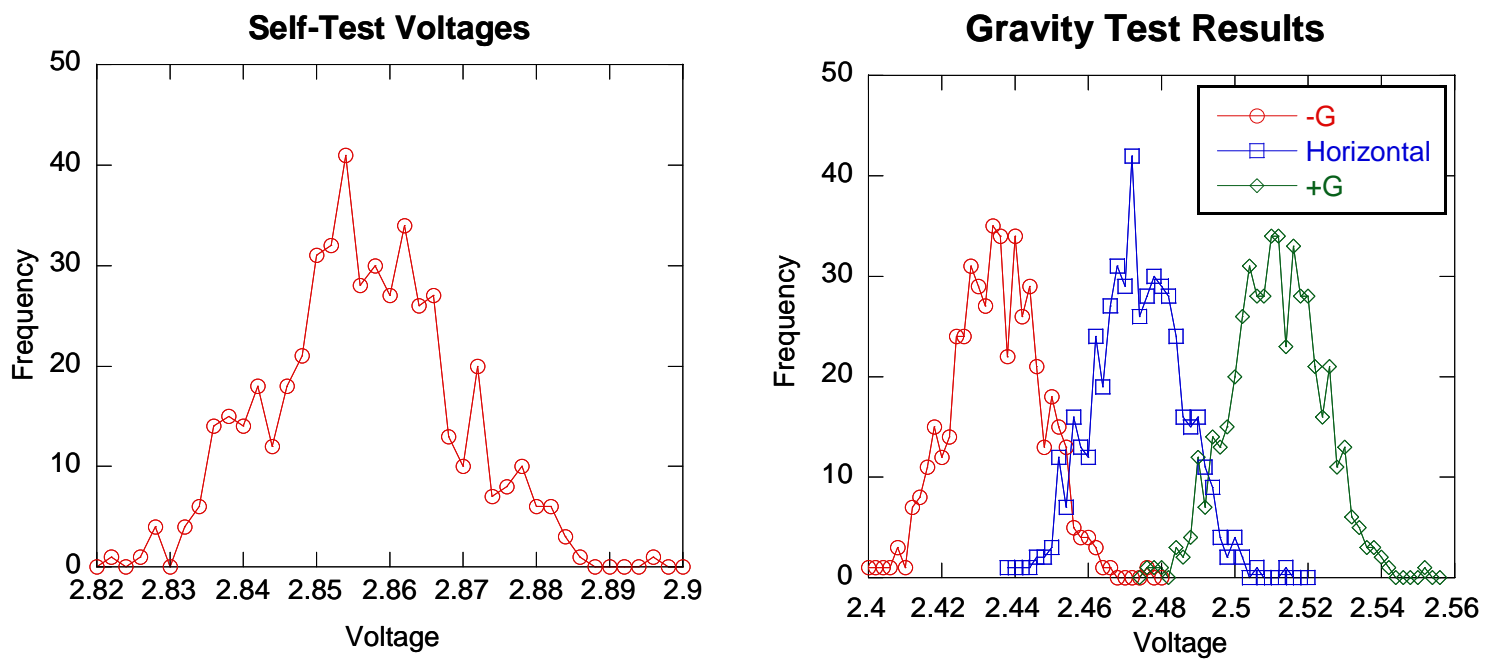

Figure 6. These histograms show the distribution of voltages for the four functionality tests. The mean of the distributions was $2.858 \mathrm{~V}, 2.475 \mathrm{~V}, 2.437 \mathrm{~V}$, and $2.513 \mathrm{~V}$ for the SelfTest, horizontal, $-G$, and $+G$ distributions, respectively. All three distributions have a standard deviation of roughly $12 \mathrm{mV}$.

\subsubsection{Fixture}

The fixture holds samples on the test and mounts directly to the drop table platform. This fixture was designed to hold samples on all six faces of the machined aluminum cube. There are specific mounts for accelerometers to measure the shock pulse-width and amplitude as shown in Figure 7. The fixture held 10 samples in each axis: $+\mathrm{G},-\mathrm{G},+\mathrm{z},-\mathrm{z},+\mathrm{x},-\mathrm{x}$. The $+\mathrm{G}$ and $-\mathrm{G}$ directions are oriented in the sensing directions of the devices. The test fixture design was intended to transmit a haversine shock pulse of constant width of $\sim 0.75 \mathrm{~ms}$ at the requested acceleration for accelerations up to 14,000 G. Figure 8 shows a side view of the sample holder with packages loaded in individual recessed areas. 


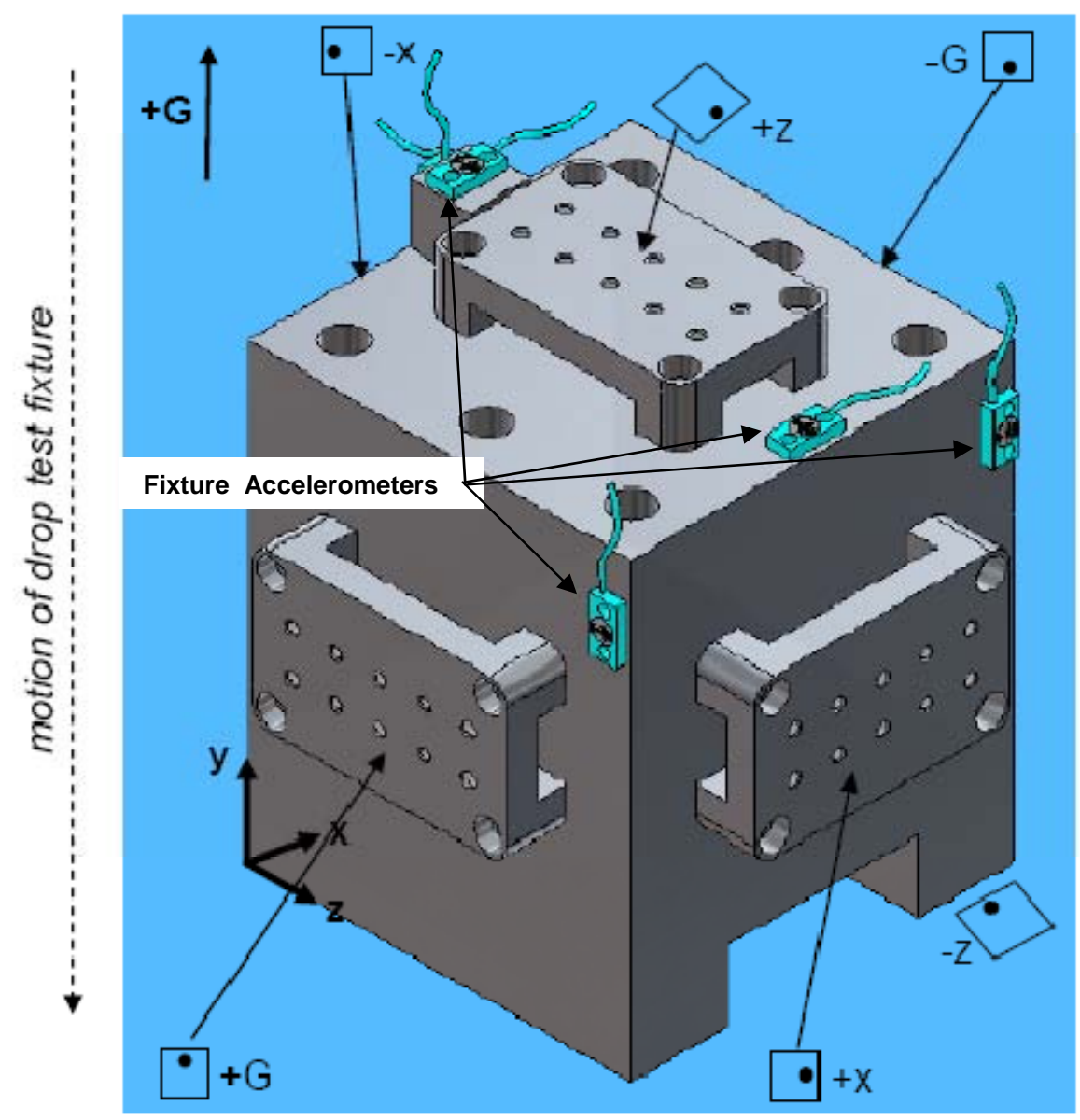

Figure 7. This drawing of the test fixture shows the defined coordinate system, the $+G$ direction, and the secure sample holder on each face. The ten single-axis samples were oriented according to the square diagram where the dot represents +sense direction.

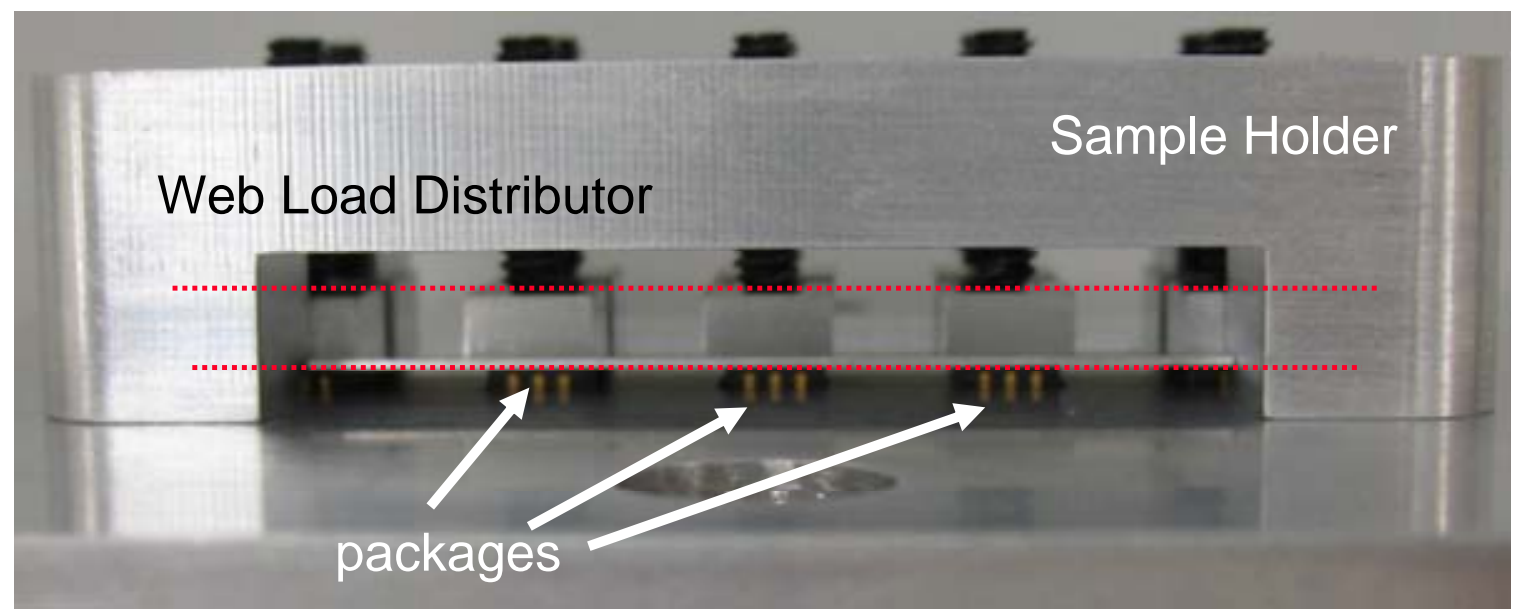

Figure 8. The sample holder is shown with packages loaded in individual recessed areas. The package contact plate was a flexible web design to distribute the load from individual set screws as shown between the dotted lines. 


\subsection{Experiment Plan/Log}

The drop table and fixture used for the shock experiments is shown in Figure 9. The goal was to incrementally increase the maximum shock load, looking for the load which could effectively damage at least $50 \%$ of the devices in a single test. This would mean that at least 5 out of the 10 on test would fail for a significant finding. The maximum shock loads chosen were 2000, 4000, $6,000,8,000,10,000,12,000$ and 14,000 $G$, within the range of testing suitable for drop table testing. The drop table test apparatus available at SNL was expected to generate a pulse width of less than $2.5 \mathrm{~ms}$, or at time periods shorter than the $400 \mathrm{~Hz}$ rated frequency response of the devices. Thus, unpowered, survive, and function tests were performed; acceleration was not monitored using the devices during the experiment.

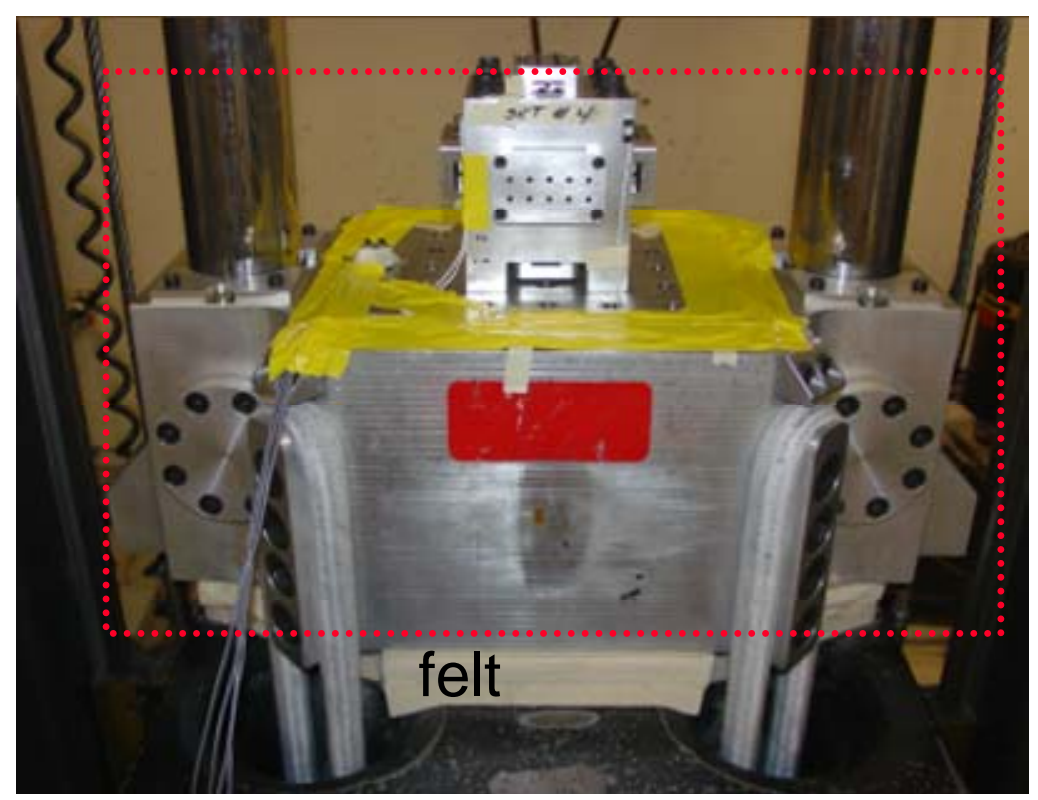

Figure 9. The fixture is shown mounted to the movable shock table. The carriage in the dotted rectangle was mechanically raised (not shown) and held at the proper height by a hydraulic brake. When the brake was released, this carriage slammed down into the felt layers (to define pulse shape) and apply the shock. 


\section{RESULTS}

\subsection{Shock Table}

The amplitude and shock pulse duration generated by the drop table experiments was characterized using test accelerometers mounted on the test carriage, as shown in figure 7, and within the sample fixture. A total of seven amplitudes ranging from $2000 \mathrm{~g}$ to $14000 \mathrm{~g}$ were characterized, their results are listed in Table I. There was good agreement between the carriage accelerometer measurements and the requested shock amplitude indicating that the shock was transmitted efficiently into the fixture. Once the shock accelerations exceeded 8000G expected deviations in the shock pulse become evident. Figure 10 plots the amplitude vs. duration of the shock pulses generated by the drop tests at 8,000 G, $10000 \mathrm{G}, 12000 \mathrm{G}$, and $14000 \mathrm{G}$. The figure shows increased ringing and shortened pulse widths at these higher requested maximum shock loads.

Table 1. Shock amplitudes and durations

\begin{tabular}{|c|c|c|}
\hline $\begin{array}{c}\text { Requested } \\
\text { Amplitude }\end{array}$ & $\begin{array}{c}\text { Measured } \\
\text { Amplitude }\end{array}$ & $\begin{array}{c}\text { Duration } \\
\text { (ms) }\end{array}$ \\
\hline $2000 \mathrm{G}$ & $2073 \mathrm{G}$ & 0.76 \\
\hline $4000 \mathrm{G}$ & $3953 \mathrm{G}$ & 0.74 \\
\hline $6000 \mathrm{G}$ & $5912 \mathrm{G}$ & 0.76 \\
\hline $8000 \mathrm{G}$ & $8605 \mathrm{G}$ & 0.74 \\
\hline $10000 \mathrm{G}$ & $9827 \mathrm{G}$ & 0.57 \\
\hline $12000 \mathrm{G}$ & $12104 \mathrm{G}$ & 0.57 \\
\hline $14000 \mathrm{G}$ & $13842 \mathrm{G}$ & 0.40 \\
\hline
\end{tabular}

The measured duration for four levels is shown in the following figure. The 10,000, 12,000, and $14,000 \mathrm{G}$ pulses have more ringing noise and shorter durations. 

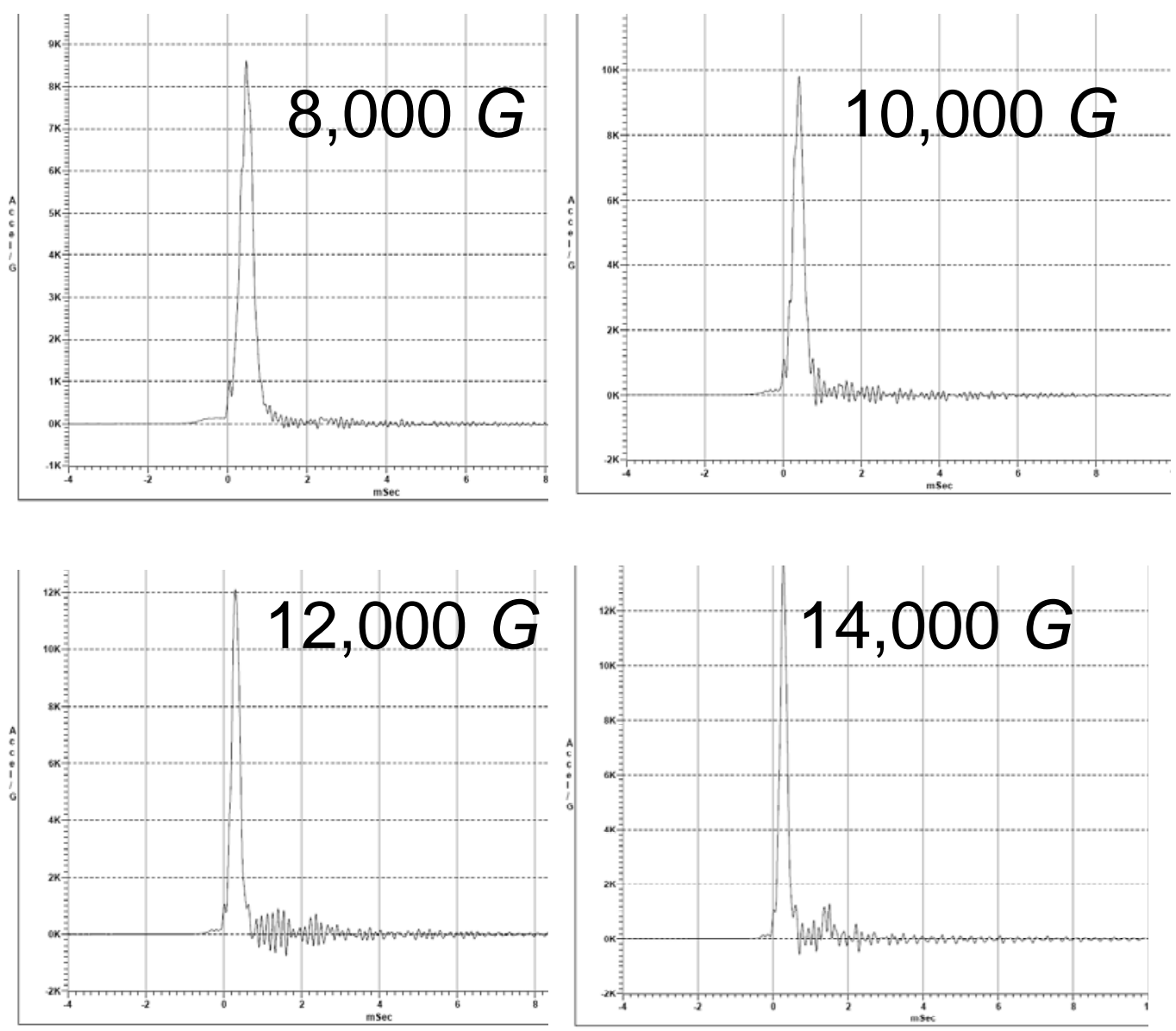

Figure 10. These are the measured amplitude and pulse durations of the carriage accelerometer.

\subsection{Testing}

The first visual evidence of damage to the packaged devices due to shock loading was noted once the shock level reached 8,000 G. The lid of the package was sometimes sheared to the side which opened the package to the air environment. This was not a result of the shock loading only, but was also related to the method used to secure the packages. The lid shear was typically accompanied by cracking in the package as observed in Figure 11. 

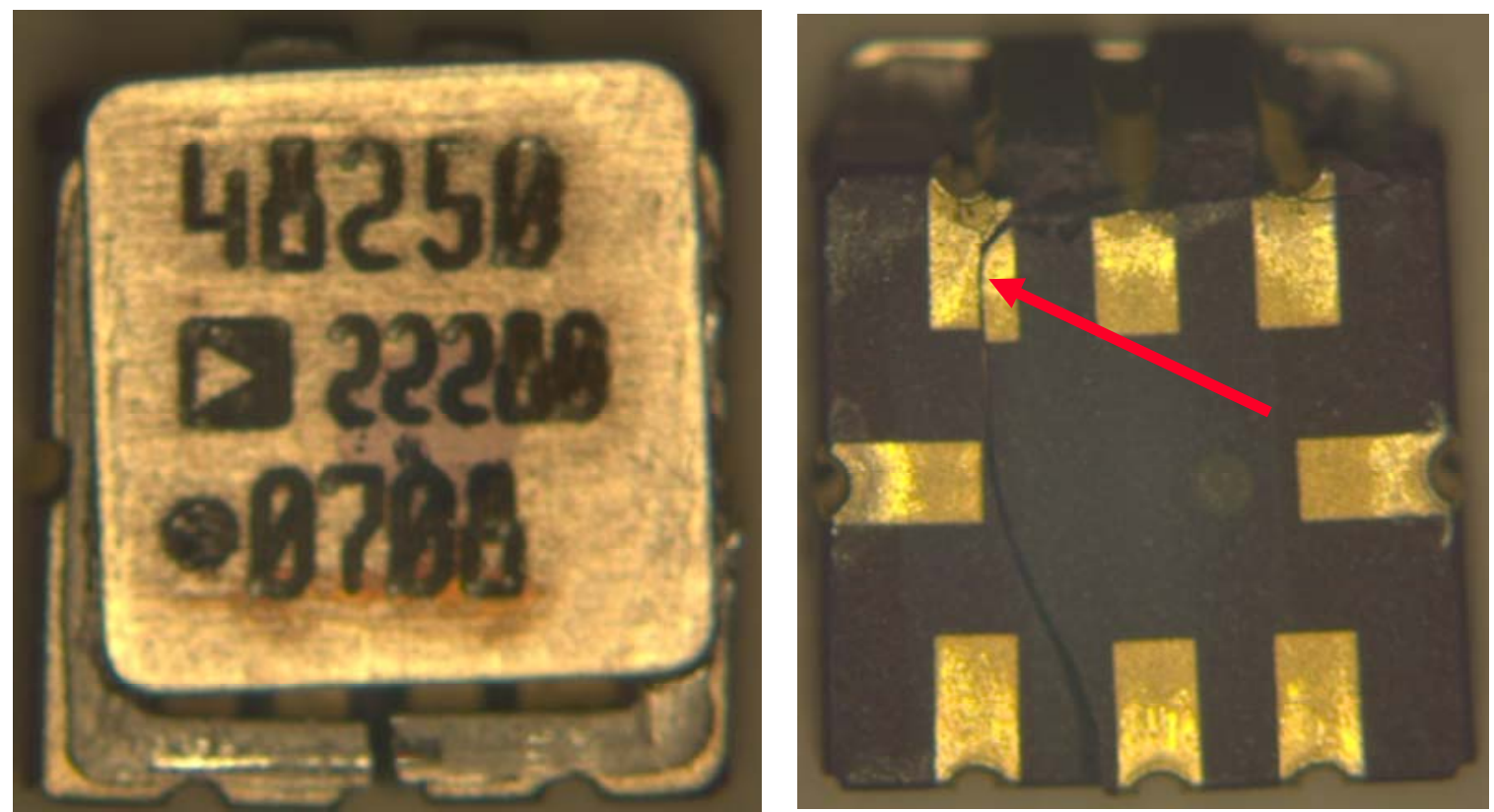

Figure 11. The image on the left is a lid-sheared package after a $14,000 \mathrm{G}$ shock in the $-\mathrm{x}$ direction. The image on the right shows the bottom of that same package. The arrow points to a crack in the package.

The samples that suffered from lid shear were typically located on the fixture near the sample holder tightening screws. As G-levels exceeding 8,000 G, were applied, the cantilever action of the web load distributors oriented in shear direction $(+\mathrm{g},-\mathrm{g},+\mathrm{x},-\mathrm{x})$ relative to the applied acceleration began to influence the experiment with some parasitic motion. Figure 12 shows evidence of that motion on the $-\mathrm{G}$ direction cube face. The rectangular imprint on the web load distributor was another indication of movement of the sample holder. Surprisingly, most of the lids sheared opposite to the direction of acceleration.
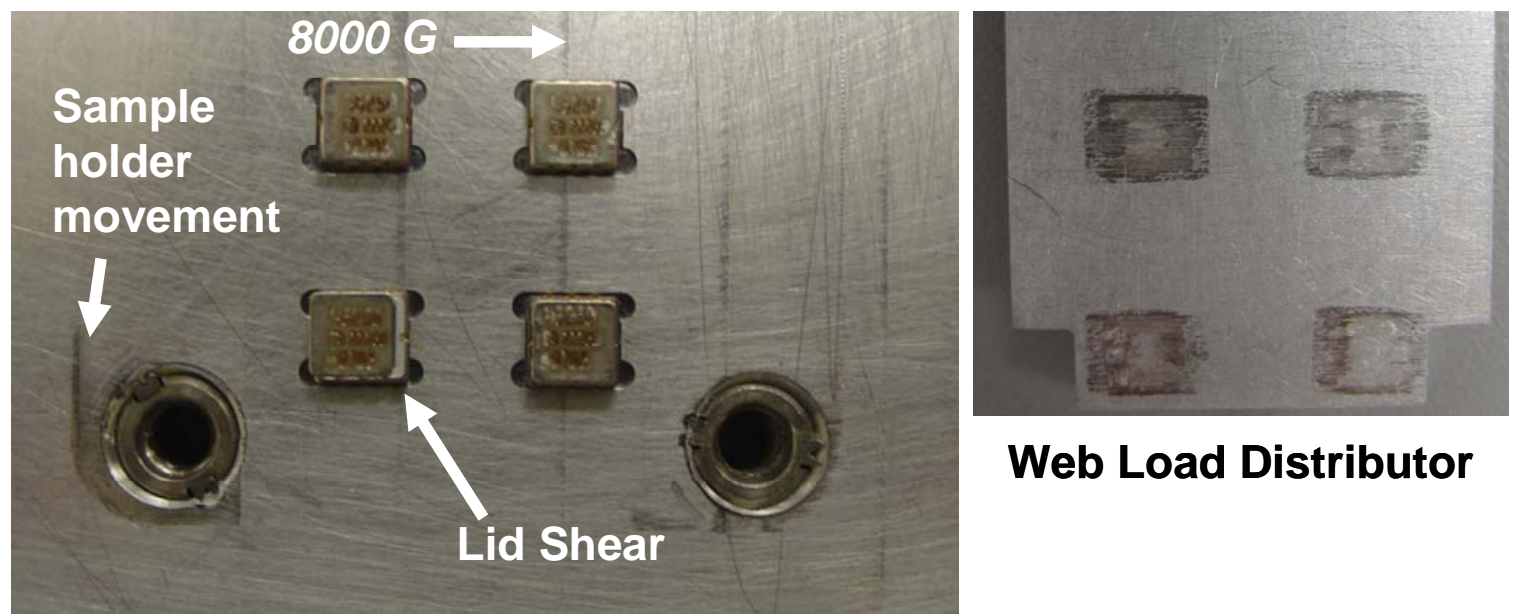

Web Load Distributor

Figure 12. The image on the left shows the samples after a shock on $8000 \mathrm{G}$ in the indicated direction. The lid shear on the lower package is pointed out. Also, there were marks showing sample holder movement after the shock. On the right is the load distributor that held the packages in place. The rectangular (rather than square) imprint indicated motion in the $\mathbf{G}$ axis. 
At the highest levels of applied shock acceleration, more damage began to accumulate on the sample holder as shown in Figure 13. The sample holder impinged on the corner support screws which left a thread imprint in the through-hole. After the 14,000 G shock, the screws were bent and had a noticeable wobble while un-screwing.

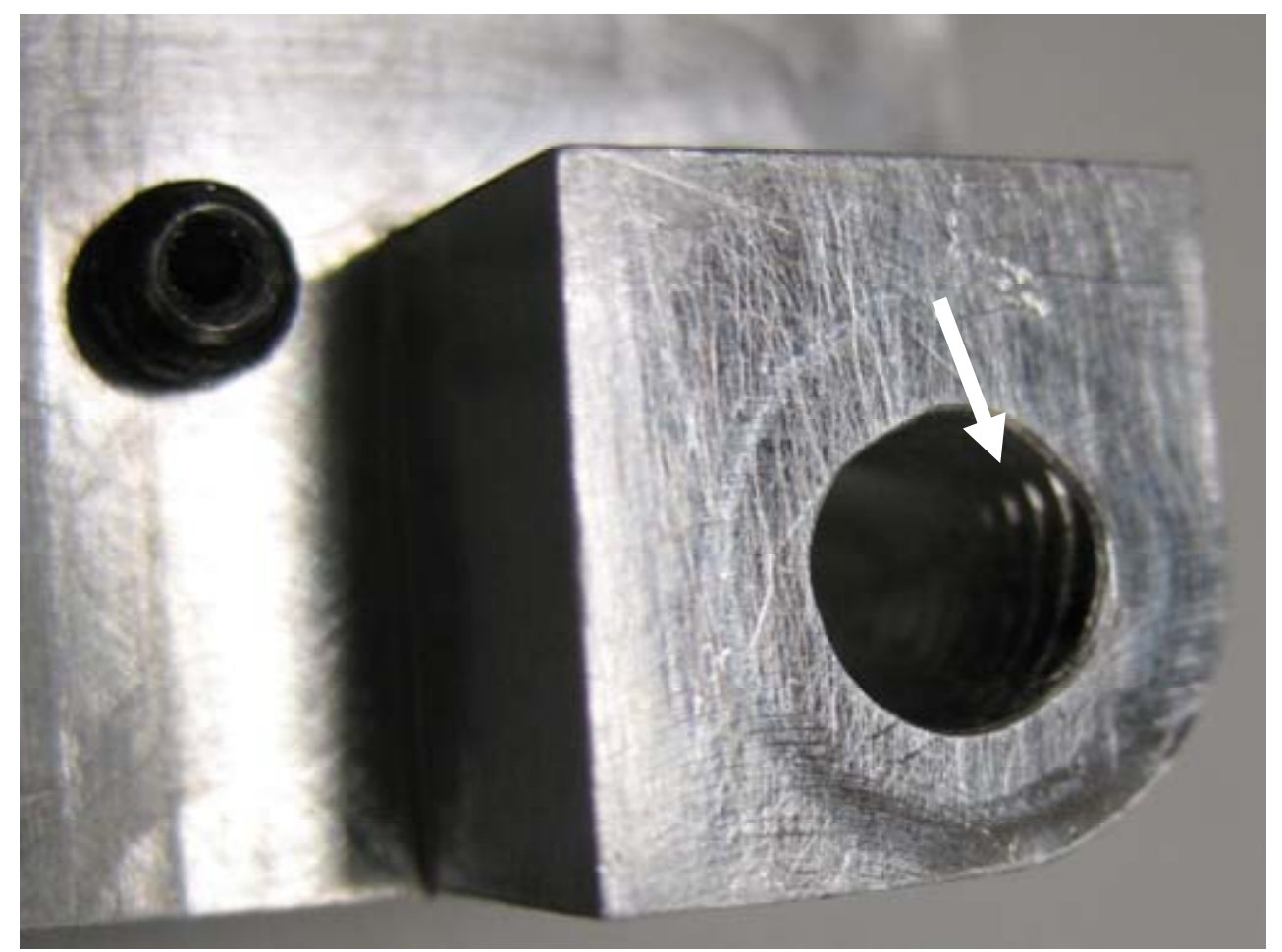

Figure 13. Higher level shocks slammed the sample holder into the support screws and left an imprint.

\subsection{Suspect Devices}

After each shock event, the fixture was un-bolted from the carriage and testing of the individual accelerometers ensued. Tests identical to those performed in the initial characterization (section 2.2.3) were then conducted. Suspect samples were categorized by a shift occurring in the voltage output during the functionality testing after the shock test, a complete failure in the self-test measurement, and observed lid shear. A list of all the suspect samples is given in Table 2. The first three levels of shock had 1 sample each with a milli-volt shift in output that caused it to fall outside the acceptable range. The value listed in the table is the average shift of the four functionality tests (Horizontal, self-test, $+G,-G$ ). Recalling that for this sensor, $1 G$ is a $38 \mathrm{mV}$ shift, thus these values represent very slight shifts and the assessment that these are "true" failures would be application/circuit specific. However, at $8000 \mathrm{G}$ (2X the operating maximum), we observe two self-test failures (g-sense functioned), one failure with a lid shear (the first one observed), and one large shift of $24 \mathrm{mV}(0.63 G)$. 
Table 2. Suspect Sample Categories from the Shock Testing

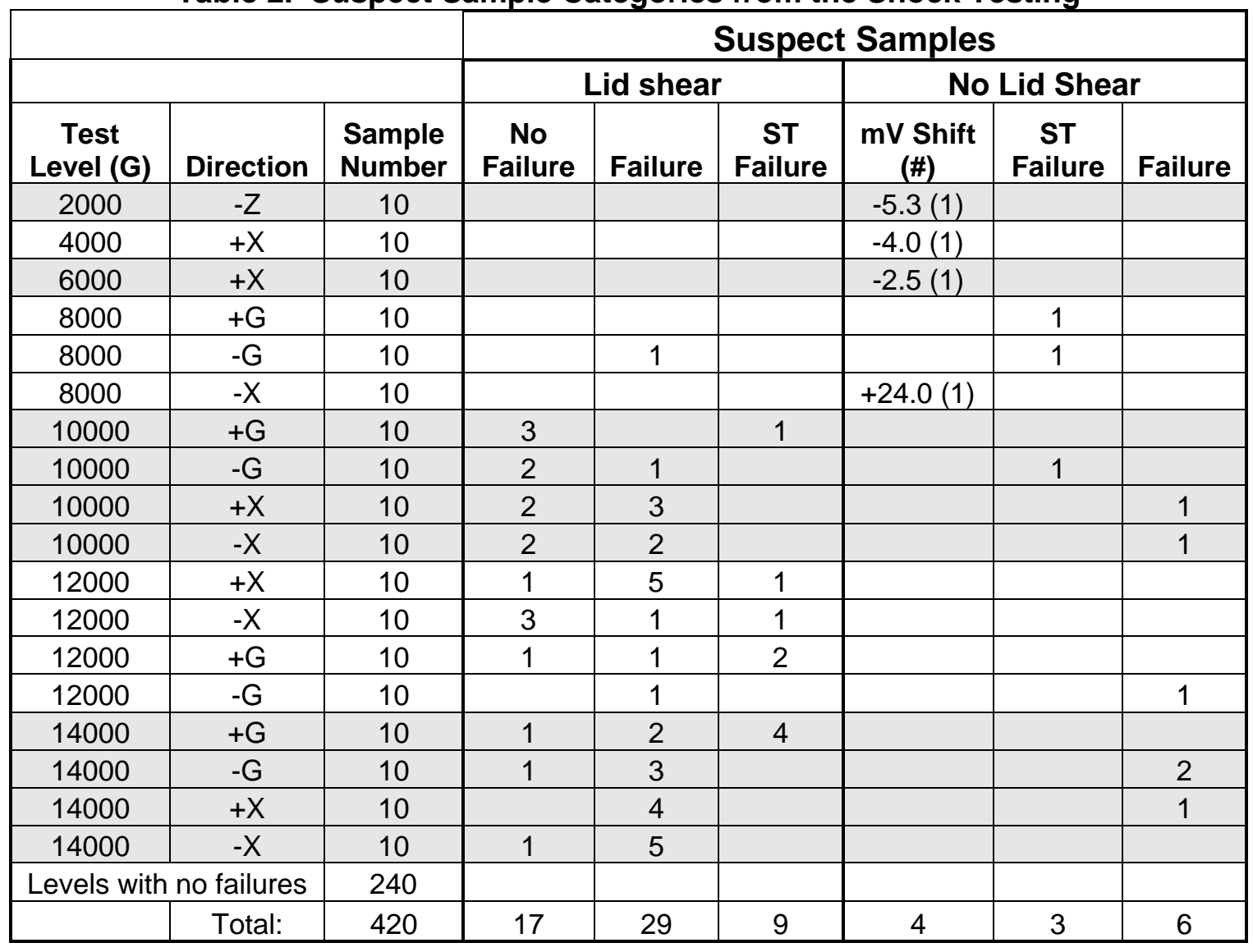

To increase the fraction of failures, the shock level was increased in the last three shocks. Unfortunately, the higher levels $(10,12,14 \mathrm{KG})$ lead to more lid shear events which may or may not lead to an operational failure of the MEMS device. The lid shear was sometimes accompanied by cracking in the ceramic package. Because the package provides the voltage to the MEMS device, a crack could interfere resulting in a failed device. Again, lid shear was caused by the test mounting technique, not the shock level. The challenge is to separate package failures caused by mounting from actual MEMS failures. That will be addressed in the next section.

Under the Lid Shear heading in Table 2 are the three states of the sample. The No Failure column is those samples that have the lid shear problem but still function. The Failure column is samples that have no or very low output in the different orientations and the ST Failure column is samples that fail the self-test but the gravity sense functionality works.

Of note in the table, for levels of $10 \mathrm{KG}$ and greater, the number of failures is always higher in the $\pm x$ direction than the $\pm G$ direction. Thus an in-plane, but off-axis acceleration was more damaging. The $\pm \mathrm{z}$ direction (normal to the package) had no real failures. The number of failures increased as the test level increased. There were $2,8,9$, and 17 failures at $8,10,12$, and $14 \mathrm{KG}$, respectively. 
There were 17 cases where the MEMS device functioned even after the lid was sheared. In many of these devices it was obvious that the environment had been breached but the MEMS device was still operational.

\subsection{Analysis of Suspect Devices}

One of the methods to address the package failed or MEMS device failed question is to remove the lid and then using probes activate a self-test. The drawback of this approach is that one can easily damage the MEMS device when removing the lid. One of the packages on the $14 \mathrm{KG},+\mathrm{x}$ direction actually crumbled around the die and provided at least one measurement. The self-test on this die failed, indicating true MEMS device failure. The package and die are shown in Figure 14.

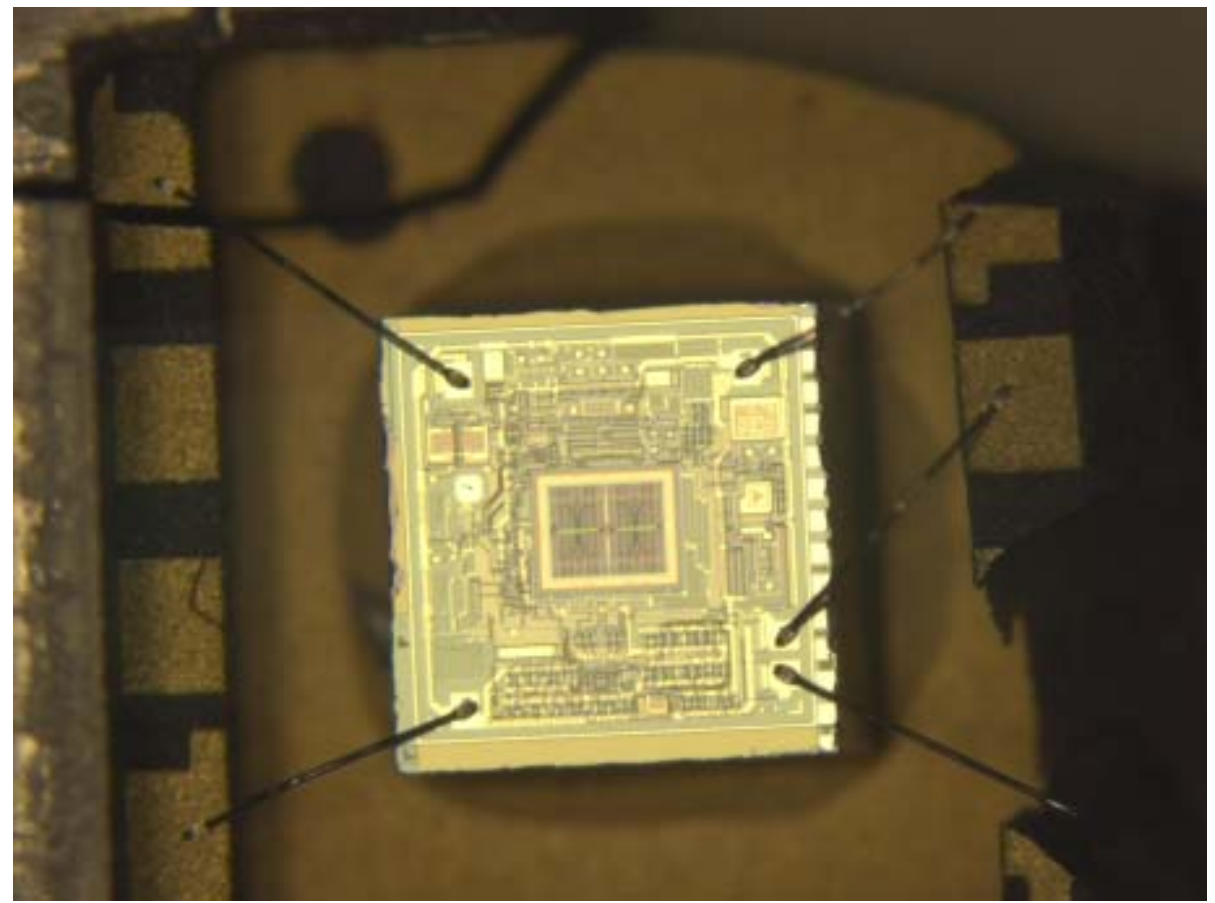

Figure 14. The AD22280 die is shown mounted in a cracked package. 


\section{CONCLUSIONS}

We have determined that these devices are robust to shock and that the margin for first failure is a factor of two. The manufacturer published a value of absolute maximum of $4000 \mathrm{G}$ and we observed first failures at $8000 \mathrm{G}$. The failure distribution indicated that an in-plane, but off-axis acceleration was more damaging than one in the sense direction.

Although a shock load where 50\% failures occurred was not achieved in this study, significant data was generated to define the range of testing for the subsequent combined thermal/shock environment investigation, as outlined in Figure 1. The proposed follow-up study would be the first to provide life-cycle environment margin and common failure modes of this class of MEMS devices. 


\section{Distribution}

10 MS0889 Tom Buchheit 1814

2 MS1069 Danelle Tanner 1749-1

1 MS0899 Technical Library, 9536 (electronic copy)

External Electronic Distribution:

Abdul Kudiya, AMRDEC_abdul.kudiya@us.army.mil

Dave Locker, AMRDEC David.Locker@us.army.mil

Judy Potter-Shields, AMRDEC

Tom Erickson, AMRDEC judy.pottershields@us.army.mil tom.erickson@us.army.mil

Don Skelton, ARDEC donald.skelton@us.army.mil James Zunino, ARDEC james.zunino@us.army.mil

Michael Bucher, NSWC

micheal.bucher@navy.mi

Michael Deeds, NSWC michael.deeds@navy.mil

Electronic Distribution:

Brad Boyce

blboyce@sandia.gov

Michael Dugger

mtdugge@sandia.gov

Ted Parson tbparso@sandia.gov

Mark Platzbecker

mrplatz@sandia.gov

Paul Butler

pcbutl@sandia.gov

Keith Ortiz

kortiz@sandi.gov

Central Technical Files

(Electronic) 


\section{Sandia National Laboratories}

